\title{
Construçóes sociais de gênero no ciberespaço: novas práticas sociais de letramento
}

Social constructions of gender on cyberspace: new
social practices of literarcy

\author{
Petrilson Alan Pinheiro \\ Universidade Federal do Rio de Janeiro - UFRJ
}

\section{Abstract}

The objective of this paper is to investigate the construction of social identities of gender consubstantiated by new social practices of literacy on cyberspace. To do so, I will take as a central point a socioconstructivist view of discourse and social identities (MOITA LOPES, 2003), whose epistemological basis is corroborated by the principle the subject relations are multiple and varied, namely, they are understood as heterogeneous and contradictory, constituent of discursive practices of which we participate. As a unit od analysis I chose a piece of conversation carried out carried out in a virtual chat room, where a boy constructs himself socio discursively as a girl when he engages himself in a literacy event with a friend.

\section{Keywords}

Social identities, gender, literacy, discourse, cyberspace.

\section{Resumo}

O objetivo de presente trabalho é o de investigar a construção das identidades sociais de gênero consubstanciada por novas práticas sociais de letramento no ciberespaço. Para tanto, tomarei como ponto central a visão socioconstrucionista do discurso e das identidades 
sociais (MOITA LOPES, 2003), cuja base epistemológica é corroborada pelo princípio de que as relações de sujeitos são múltiplas e variadas, isto é, são entendidas como heterogêneas e contraditórias, constituintes das práticas discursivas das quais participamos. Como unidade de análise, escolhi uma conversa realizada numa sala de bate-papo virtual, onde um menino se constrói sociodiscursivamente como uma menina ao se engajar em um evento de letramento com uma amiga.

\section{Palavras-chave}

Identidades sociais, gênero, letramento, discurso, ciberespaço. 
No passado, podiam-se acusar os historiadores de querer conhecer somente as "gestas dos reis". Hoje, é claro, não é mais assim. Cada vez mais se interessam pelo que seus predecessores haviam ocultado, deixado de lado ou simplesmente ignorado (GINSBURG, Carlo, 1987, p. 15).

\section{Introdução}

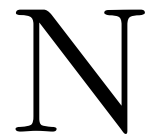

os últimos anos, houve mudanças bastante significativas nos jogos relacionais que se traduzem em formas interativas de sociabilidade entre os mais variados conjuntos de atores sociais. Tais mudanças passaram a ocorrer, sobretudo, em virtude do grande fluxo de informação, bem como do seu fácil acesso, o que passou a disponibilizar diversas formas de ver e viver a experiência humana (FRIDMAN, 2000), ao mesmo tempo em que vêm contribuindo para propiciar um repensar e uma redefinição das relações e identidades sociais construídas nos contextos locais de atuação.

Nesse sentido, a mídia, sobretudo a mídia eletrônica, torna-se um espaço central não só para a difusão da informação renovada, como também para a permanente (re)construção das identidades sociais. Em outras palavras, na contemporaneidade, o processo de construção das identidades sociais está cada vez mais dependente de um grande fluxo de materiais simbólicos constituídos por meio das mais diversas práticas de letramento nas quais os sujeitos se engajam para construir sentido na vida social.

Pretendo, por meio deste trabalho, focalizar a construção da identidade social de gênero num evento de letramento não escolar na mídia eletrônica. Analisarei como um menino se (re)constrói discursivamente como uma menina ao se engajar interacionalmente com uma amiga numa sala de bate-papo virtual na Internet.

O presente estudo toma, portanto, como ponto central uma visão socioconstrucionista do discurso e das identidades sociais (MOITALOPES, 2003), cuja base epistemológica é corroborada pelo princípio de que as relações de sujeitos e de sentidos são constituídas sócio-historicamente e, por isso, "são entendidas como múltiplas e heterogêneas, contraditórias, e em fluxo, constituintes das práticas discursivas nas quais atuamos" (SIGNORINI, 1998, p. 92).

Abordarei, então, na base teórica desta pesquisa, o letramento como prática social e sua aplicabilidade em múltiplos contextos, a questão da construção das identidades sociais, e os (hiper)textos virtuais como novos letramentos; em 
seguida, apresentarei o contexto e metodologia de pesquisa; passarei, então, a analisar os dados, tomando por base os construtos teóricos que norteiam o presente estudo; e encerrarei o trabalho com algumas considerações finais.

\section{Letramentos e Construção Identitária}

Pesquisas e abordagens relativamente recentes no campo do letramento (GRAFF, 1994; KLEIMAN, 1995; SCRIBNER \& COLE, 1981; SIGNORINI, 1998; STREET, 1995) passaram a não mais enfocar o letramento como fenômeno universal, indeterminado social e culturalmente e responsável pelo progresso, civilização, acesso ao conhecimento e mobilidade social, visto que, conforme assevera Signorini (1995, p. 21),

Essa idéia de "letra" como a chave para se decifrar (ou conquistar) o "mundo", independentemente de variáveis contextuais de qualquer natureza, nos remete a um mito consolidado nos dois últimos séculos via tradições culturais ocidentais de prestígio e que é constitutivo não só dos discursos institucionais sobre as vantagens de se saber ler e escrever, como também do senso comum: o "mito do letramento".

A partir dessa visão, Kleiman (1995), com base em Street (1995), distingue dois modos de se pensar o letramento os quais vêm aparecendo nas pesquisas das últimas duas décadas: o "modelo autônomo" e o "modelo ideológico". O primeiro, que se coaduna com a concepção tradicional de letramento, segundo Kleiman (1995, p.21), "pressupõe que há apenas uma maneira de o letramento ser desenvolvido, sendo que essa forma está associada quase que casualmente com o progresso, a civilização, a mobilidade social". Pode-se, por conseguinte, pensar que essa concepção de letramento se define, principalmente, por pressupor uma maneira única e universal de desenvolvimento do letramento, quase sempre associada a resultados e efeitos civilizatórios, de caráter individual (cognitivos) ou social (tecnológicos, de progresso e de mobilidade social).

Já no “modelo ideológico”, Kleiman (1995, p.21), baseada em Street (1995) pondera que:

As práticas de letramento, no plural, são social e culturalmente determinadas e, como tal, os significados específicos que a escrita assume para um grupo social dependem de contextos e instituições em que ela foi adquirida. Não pressupõe, esse modelo, uma relação 
causal entre letramento e progresso ou civilização, ou modernidade, pois, ao invés de conceber um grande divisor entre grupos orais e letrados, ele pressupõe a existência e investiga as características de grandes áreas de interface entre práticas orais e letradas.

Consequientemente, ao contrário do modelo autônomo, os pesquisadores que adotam a perspectiva do modelo ideológico vão investigar práticas (plurais) de letramento, contextualizadas em esferas sociais específicas (grupos, instituições, contextos), onde funcionamentos comunicativos e discursivos particulares da esfera social colocarão numa pluralidade de relações complexas, dentro de práticas letradas, oralidade e escrita, que, portanto, não podem mais ser vistas de maneira dicotômica.

Podemos, então, argumentar que as relações de causa e efeito entre poder, acesso (e sucesso) social e saber escolarizado, historicamente relacionadas com o racionalismo iluminista e a universalização da racionalidade científica e tecnológica nas sociedades ocidentais modernas, passam, no modelo ideológico, a ser questionadas. Dentro dessa perspectiva de letramento, portanto, as próprias práticas letradas escolares passam a ser consideradas apenas como um tipo de prática social de letramento (ou uma agência de letramento entre tantas outras como a família, a igreja, o local de trabalho, etc.(KLEIMAN, 1995)), que, embora continue sendo, nas sociedades complexas, um tipo dominante - relativamente majoritário e abrangente -, desenvolve apenas algumas capacidades e não outras.

A partir desse enfoque, surgem, então, alguns conceitos fundamentais para que se possa compreender o letramento com prática social, como os de prática de letramento e evento de letramento (BLOOME, 1993; BLOOME \& BAILEY, 1992; KLEIMAN, 1995; LANKSHEAR \& GEE, 1997; LANKSHEAR \& KNOBEL, 1997; STREET, 1995). As práticas de letramento seriam as mais variadas atividades e processos de ordem sociocultural que envolvem, de alguma forma, o uso da linguagem para fazer sentido tanto na fala quanto na escrita. Os eventos de letramento, por sua vez, são entendidos como um conjunto de práticas sociais, construídas interpessoalmente, cujos sentidos estão sempre situados nos próprios eventos e nas possíveis interações deles provenientes, não de forma isolada na mente das pessoas (BLOOME \& BAILEY, 1992). Isso justifica o fato de eventos serem responsáveis pela construção das identidades sociais dos sujeitos, uma vez que, nos eventos, as pessoas estão constantemente negociando suas identidades e relações sociais (GOFFMAN, 1967). 
Desse modo, podemos afirmar que existe, de fato, uma inter-relação entre letramentos e os processos de construção das identidades sociais, ou, segundo Moita Lopes (2005, p. 50), "tornar-se letrado é um modo de construir que você é ou está sendo nas práticas sociais ao mesmo tempo que o processo de construção da identidade social é parte do processo de se tornar letrado uma vez que nossas histórias sociais são intrínsecas aos processos de construção de significados nos quais nos engajamos".

Por conceber a natureza da linguagem como constitutivamente dialógica (BAKHTIN, 1981), por meio da observação das complexas relações entre história e embates ideológicos na constituição identitária do ser humano, entendemos que a construção do conhecimento na vida social constitui um processo complexo e, não pouco freqüentemente, marcado por contradições.

Ao tentar buscar, então, fundamentos para refletir sobre a construção do conhecimento na vida social, estamos adotando uma posição socioconstrucionista acerca dos discursos e das identidades sociais (MOITA LOPES, 2003), cujo construto teórico se baseia em uma visão constante de incompletude, fluidez e em uma atitude dialógica perante os discursos analisados, reconhecendo as inúmeras ideologias que os perpassam, a sua especificidade perante uma situação material de produção específica e, portanto, a impossibilidade de submetê-los à análise por meio de uma teoria acabada sem perder de vista a sua complexidade.

Delineia-se, a partir dessa visão pós-modernista, uma concepção de sujeito, bem como de letramento, que passa a ser visto, segundo Luke (1997, p. 22), como "situado num corpo social coletivo que é constituído através / na diferença (identitária ou local), e não na mesmice”. Com isso, passa-se a adotar uma perspectiva de linguagem que enxergue além da situação material de produção na qual os enunciados concretos são proferidos, buscando, na história, na cultura, na vida e no conhecimento compartilhado dos participantes e dos contextos sociais nos quais estão inseridos, suas construções identitárias que, por serem atribuições situadas sócio-historicamente, são sempre "relações de sujeitos e de sentidos e seus efeitos são múltiplos e variados, isto é, são entendidas como heterogêneas, contraditórias, e em fluxo, constituintes das práticas discursivas nas quais atuamos" (ORLANDI, 2001, p. 21).

Podemos inferir, então, a partir do que foi exposto, que as concepções postuladas até aqui em relação à linguagem colocam a interação com o outro no mundo social como central no processo de constituição da consciência. O ser humano, portanto, constitui-se na e por meio da alteridade, e todas as atividades 
e papéis por ele desempenhados, nas mais diversas esferas do mundo social, encontram-se impregnados do discurso de outrem (FAIRCLOUGH, 1992). Dessa forma, ao se tomar o diálogo entre os interactantes como um palco de batalhas ideológicas, visões de mundo e conhecimentos entram em constante conflito visando engajar discursivamente os participantes em um processo de reflexão sobre a própria ação. Por isso, consideramos fundamental compreender o discurso como o meio através do qual seja possível entender que a nossa participação nas mais diversas esferas da vida social determina quem somos, como avaliamos o outro e como pensamos que esse outro nos avalia, desencadeando um processo ininterrupto de (re)construção de identidades.

Nesse sentido, as ideologias reveladas no discurso dos interactantes são diretamente influenciadas pela participação deles em diferentes comunidades de prática (LAVE \& WENGER, 2002), ao mesmo tempo em que revelam as identidades por eles constituídas no decorrer das interações com o(s) outro(s) nessas comunidades. À medida que essas identidades entram em conflito, são questionadas e analisadas, o diálogo pode se tornar um espaço para (re)construção de identidades para todos os participantes envolvidos.

Pode-se propor, com base nessa visão, que a nossa participação nas práticas de diferentes comunidades leva à construção de identidades em relação a essas comunidades. Sob esse prisma, participar, por exemplo, de uma sala de bate-papo virtual na Internet constitui-se, ao mesmo tempo, em ações e formas de pertencimento. Tal participação influencia não apenas o que fazemos, mas quem somos e a forma como interpretamos aquilo que fazemos.

Podemos inferir, então, que todos nós pertencemos a diversas comunidades de prática - em casa, no trabalho, na escola, na Internet -, comunidades essas que mudam no curso de nossas vidas. A forma como participamos dessas comunidades representa experiências de aprendizagem e, logo, de constituição de identidades. Por isso, o processo de (re)construção de identidades por meio das sucessivas formas de participação nas comunidades de prática determina nossa trajetória nessas comunidades, fazendo da identidade um processo de vir a ser, um constante tornar-se. Por relacionar presente, passado e futuro, a noção de identidade implica a idéia de constante movimento, e não de destino fixo (FAIRCLOUGH, 1992).

Vista como trajetória, as nossas identidades, portanto, são constituídas historicamente (MOITA LOPES, 2003), incorporando o passado e o futuro no processo de negociação do presente, permitindo-nos selecionar o que contribui 
e o que permanece marginal para a constituição da nossa identidade. Cada comunidade de prática é, dessa maneira, (LAVE \& WENGER, 2002) um campo de possíveis trajetórias, de possíveis passados e possíveis futuros em que os participantes podem se engajar.

É mister, portanto, pensar a constituição identitária de gênero (foco de estudo do presente trabalho) como uma construção social (assim como as de sexualidade, raça, etnia, etc), ou seja, como uma experiência de pertencimento múltiplo, que ocorre por meio de uma relação constante entre elementos globais e elementos locais. Devemos, por conseguinte, passar a adotar a visão de letramento crítico, em que, segundo Gilbert (1997, p. 60), "a construção social de gênero por meio de práticas de linguagem fornece uma janela óbvia através da qual se questiona a autoridade de um texto, e uma janela óbvia através da qual se explora como as práticas sociais e as práticas de linguagem estão entrelaçadas".

\section{Os (Hiper)Textos Virtuais: Novos Tipos de Letramento}

Ao se pensar sobre letramento, a idéia que se tem, de imediato, é única e exclusivamente a escola e os meios tradicionais nela desenvolvidos para aprender a ler e escrever. Contudo, temos assistido, nos últimos anos, a uma explosão de novas práticas de letramento, consubstanciadas pelas novas tecnologias, que vêm fazendo parte, de forma cada vez mais crescente, das mais diversas esferas da vida social. Por isso, quando, hoje, se reflete acerca de tipos de letramentos, pode-se mencionar uma multiplicidade de novos tipos de interações por meio de textos e hipertextos virtuais, gerados na / pela mídia eletrônica ao lado do, então, letramento "tradicional" escolar que, por sua vez, passa a ser apenas mais um tipo de letramento (LANKSHEAR \& KNOBEL, 1997).

Antes de seguir adiante com os letramentos tecnológicos, tratarei da questão dos (hiper)textos.

Para buscar apreender um significado sobre o termo "hipertexto", reporto-me a uma definição fornecida por Marchuschi (1999, p. 1), que o caracteriza como "um processo de escritura / leitura eletrônica multilinearizado, multiseqüencial e indeterminado, realizado em um novo espaço". Por fornecer, então, uma multiplicidade de leituras e correlação entre outro(s) (hiper)texto(s), para que se possa fazer uma leitura proveitosa de umhipertexto, é preciso que haja "um grau maior de conhecimentos prévios e maior consciência quanto ao buscado, já que é um permanente convite a escolhas muitas vezes inconseqüientes" (MARCHUSCHI, 1999, p. 2). 
Contudo, podemos ir mais longe no que tange ao hipertexto digital, pois este, diferentemente do hipertexto concebido dentro de uma concepção clássica, conforme assevera Lévy (1996, p.44),

Permite novos tipos de leituras (e de escritas) coletivas. Um continuum variado se estende assim entre a leitura individual de um texto preciso e a navegação em vastas redes digitais no interior das quais um grande número de pessoas anota, aumenta, conecta os textos uns aos outros por meio de ligações hipertextuais [...] O hipertexto digital seria portanto definido como uma coleção de informações multimodais disposta em rede para a navegação rápida e "intuitiva".

De fato, as novas produções (hiper)textuais, consubstanciadas pelas novas tecnologias, permitem-nos reavaliar e até (re)construir nossas práticas sociais, podendo fazer com que elas "mudem e alterem de forma tal a constituírem um novo evento" (MARCHUSCHI, 1999, p. 3). Ou, conforme ponderam Lankshear \& Knobel (1997, p. 153):

Práticas sociais baseadas no texto digital têm fornecido um novo escopo para experimentação e criatividade evidentes no desenvolvimento de novos vocabulários, sinais e códigos pelos participantes. Isso comprova mais uma vez o desejo humano pela atividade, pela invenção e pela prática transformativa.

Se ser letrado é, por conseguinte, estar envolvido em práticas discursivas para construir sentidos, e se, de fato, está ocorrendo na contemporaneidade uma integração cada vez maior para se construir sentido entre o que é o textual, visual, áudio, espacial, comportamental, etc (COPE \& KALANTZIS, 2000), então devemos pensar que o poder de se engajar em uma multiplicidade de discursos, de modo a constituir-se como um ser discursivo na vida social, já é em si um ato de se tornar letrado, uma vez que é a partir do discurso que podemos (re)construir quem somos nas mais diversas comunidades de prática das quais fazemos parte.

Nesse cenário, a mídia eletrônica pode ser, então, pensada como uma comunidade de prática que pode possibilitar aos interactantes, até mais facilmente que outros meios, experimentarem outras vidas, onde as distâncias se anulam, onde o local passa a co-existir como global. A esse respeito Du Gay (1997, p. 26) assevera que: 
A nova mídia eletrônica não apenas possibilita a expansão das relações sociais pelo tempo e espaço, como também aprofunda a interconexão global, anulando a distância entre as pessoas e os lugares, lançando-as em um contato intenso e imediato entre si, em um "presente" perpétuo, onde o que ocorre em um lugar pode estar ocorrendo em qualquer parte (...) Isto não significa que as pessoas não tenham mais uma vida local - que não mais estejam situadas contextualmente no tempo e espaço. Significa apenas que a vida local é inerentemente deslocada - que o local não tem mais uma identidade "objetiva" fora de sua relação com o global.

Considerando-se que os interactantes que participam desta pesquisa pertencem a diferentes comunidades de prática, mas que, ao mesmo tempo, estão pertencendo a uma mesma comunidade de prática virtual na Internet, e que cada um está construindo sua trajetória em todas essas comunidades de forma específica, o diálogo entre eles pode ser um espaço privilegiado de vir a ser ao fazerem do processo de construção do conhecimento no diálogo entre eles uma experiência de (re)construção de identidades. Ou, nas palavras de Lévy (1996, p.23):

A virtualização não é uma desrealização (a transformação de uma realidade num conjunto de possíveis), mas uma mutação de identidade, um deslocamento do centro de gravidade ontológico do objeto considerado: em vez de se definir principalmente por sua atualidade ("uma solução"), a entidade passa a encontrar sua consistência essencial num corpo problemático.

Assim como podemos pensar o processo de constituição de identidades a partir da nossa participação, formas de pertencimento e trajetórias em diferentes comunidades de práticas, Gee (2001) postula que todas as pessoas possuem identidades múltiplas construídas principalmente pela forma como são avaliadas pelo(s) outro(s) nos mais diversos contextos sociais. Como essa avaliação pode variar de contexto a contexto e de momento a momento na interação, o processo de constituição de identidades é marcado por instabilidades e ambigüidades. "Por isso a virtualização é sempre heterogênese, devir outro, processo de acolhimento da alteridade" (LÉVY, 1996, p. 25).

No entanto, talvez o que o mundo virtual nos ofereça de mais interessante, no que diz respeito à constituição identitária, seja o fato de nós podermos ter acesso 
não a uma, mas a várias novas formas de viver a experiência humana no mesmo espaço de tempo. Ou, conforme assevera categoricamente Turkle (1996, p. 160):

O eu não está mais simplesmente desempenhando diferentes papéis em diferentes cenários, algo que as pessoas experimentam quando, por exemplo, alguém acorda como um amante, toma café como uma mãe, e dirige para o trabalho como um advogado. A prática de vida do mundo virtual é a de um eu distribuído que existe em muitos mundos e que desempenha muitos papéis ao mesmo tempo.

É, portanto, a partir dessa multiplicidade de possibilidades que nos são disponibilizadas pela mídia eletrônica, e da forma como fazemos uso disso por meio da linguagem, que podemos pensar em (re)criar nossos mundos sociais, nosso relacionamento com o outro e nossas ideologias, assim como podemos pensar que tudo isso está intrinsecamente relacionado com as nossas identidades sociais de gênero, raça, sexualidade, etc. que constituem e são constituídas pela atividade humana nas mais variadas esferas do mundo social, em especial no mundo virtual. Por isso, ao relacionar os conceitos de letramentos, identidades social, comunidades de prática e de (hiper)textos virtuais, pretendo dar conta de questões de ordem social, cultural e histórica, dentro de um processo reflexivo entre os interactantes participantes do presente estudo, visto que o diálogo entre eles, o espaço virtual e as práticas de letramento em que estão inseridos passam a ser os meios através dos quais se pode refletir acerca do processo de (re)construção de suas identidades sociais.

\section{Contexto e Metodologia de Pesquisa}

O contexto de pesquisa do presente trabalho se constitui por meio de práticas discursivas entre dois sujeitos que interagem entre si numa sala virtual de "bate-papo" na Internet, onde pessoas se convidam e se reúnem virtualmente para conversar, fazer amigos, etc.

Os dados foram provenientes de um estudo de caso com Cris, um dos alunos de uma turma do segundo ano do Ensino Médio de uma escola da rede pública do Estado do Rio de Janeiro no ano de 2005.

Escolhi para este estudo analisar uma das conversas, em forma de texto escrito, que estivesse diretamente relacionada com a temática das identidades sociais de gênero que norteia a presente pesquisa. $\mathrm{O}$ foco da análise centra-se, portanto, na interação 
entre dois interactantes: Cris, um menino que se constrói socialmente numa comunidade de prática virtual como uma menina, e Sabrina, sua amiga virtual.

A motivação em realizar um estudo de caso especificamente com ele surgiu, primeiramente, de observações minhas acerca de seu comportamento em relação aos seus colegas de turma em sala de aula durante algumas palestras sobre sexualidade que ministrei para a turma e, já numa segunda etapa, após uma entrevista por meio da qual pude conhecer melhor meu sujeito de pesquisa. Cris, então, permitiu-me que copiasse algumas de suas conversas na sala de "batepapo" virtual com uma de suas amigas (Sabrina), registradas num dos computadores da sua escola, para a realização deste estudo.

Quanto à metodologia, decidi adotar, neste estudo, uma visão interpretativista de pesquisa, visto que, neste tipo de investigação, reconhece-se o conhecimento como algo construído na interpretação da linguagem. Por isso, percebe-se que não se pode realizar este tipo de pesquisa ignorando "a visão dos participantes do mundo social, caso se pretenda investigá-lo, já que esta que o determina: o mundo social é tomado como existindo na dependência do homem" (Moita Lopes, 1994, p.331). Em outras palavras, na pesquisa de base interpretativista, os instrumentos deixam de ser vistos como um fim em si mesmo para se tornarem uma ferramenta interativa entre os sujeitos envolvidos.

É, portanto, com base nesse conceito de pesquisa e pressupostos epistemológicos discutidos na base teórica deste trabalho, que me propus a realizar o presente estudo interpretativista de cunho etnográfico, com o fito de situá-lo não como uma mera aplicação de certos métodos, mas sim como um estilo de investigação comprometido com um tipo de pesquisa que possibilite compreender a experiência humana por meio da co-construção do conhecimento entre os sujeitos envolvidos.

\section{Análise dos Dados}

Com o intuito de realizar um trabalho mais específico, selecionei para a presente análise apenas uma parte da conversa escrita numa sala virtual de "batepapo" entre os interactantes Cris e Sabrina (dividida, para fins de análise, em dois excertos) que tematiza aspectos relativos à construção social de gênero.

O primeiro excerto se inicia com a interactante Sabrina contando para Cris a respeito de um menino da escola que, no dia anterior, chamou muito a sua atenção por ser, segundo ela, muito bonito. Sabrina, então, pede conselhos a Cris para tentar, de alguma maneira, conhecê-lo. 


\section{Excerto 1:}

01 CRIS - oi, Sabri, td bem com vc?

02 SABRINA - ai, td ótimo, amiga!!! vi hj na escola um gatinho lindo, mto fofo!!!

03 CRIS - como? me conta!!!

04 SABRINA - ah eu tava no pátio com as minha amigas aí eu vi aquele menino tdo fofinho aí a gente falou dele, olha, geral ficou louca por ele, assim, ele é td de bom!!! Ai, já to azarando ele tem um tempo, mas não sei. me ajuda, amigaaa!!!

05 CRIS - pede as menina pra te apresentar!

06 SABRINA - uuuu... ai, será??? ?tô até nervosa!!! manhã eu falo com elas. eu vou pega aquele gatinho pra mim!!!. eu posso te contar tudo, neh... ai, mas fala de vc!!!

07 CRIS - na mesma! tô toda enrolada na escola, matemática, não entra na cabeça!!!

08 SABRINA - ai, fala sério!!!!

A interactante Sabrina expõe o fato ocorrido no dia anterior a Cris e pede que ela a ajude de alguma forma. Sabrina, portanto, posiciona-se discursivamente como o foco central na interação, tomando para si o turno e esperando de Cris apenas alguma atitude responsiva em relação ao assunto do qual está tratando. Sabrina, após ter ouvido o que supostamente esperava de Cris em relação ao modo como agiria para se aproximar do menino no qual estava interessada ("pede as menina pra te apresentar!" - linha 05), emite uma resposta não propriamente verbal, típica da prática de letramento na qual os interactantes estão envolvidos, que se aproxima da oralidade, que sinaliza para o outro (Cris) seu posicionamento de dúvida ao que foi dito ("uuu..." - linha 06), seguido do uso de um emoticon sorrindo (uma espécie de bonequinho virtual que se caracteriza como um tipo de elemento hipertextual), que se presta, em diálogos realizados nas salas de bate-papo virtuais, para mostrar algum tipo de aprovação de alguma idéia. No exemplo, Sabrina o usou com o intuito de deixar claro para Cris que aprovou seu conselho (? - linha 06).

Apesar de Sabrina ter tentado dar voz a sua amiga no final do excerto, Cris não se estendeu em sua fala, reportando-se somente a uma dificuldade sua com uma das disciplinas da escola, o que, de uma certa forma, gerou uma 
frustração em Sabrina, que apenas proferiu uma atitude responsiva de encerramento do assunto ("ai, fala sério" - linha 08).

Contudo, analisando o posicionamento discursivo de Cris em relação a sua amiga, podemos observar aspectos que a constroem sociointeracionalmente como uma menina. Primeiramente, verifica-se, lingüisticamente, que Cris faz uso de dois vocábulos marcados com o morfema de gênero $a$, com o intuito de enfatizar sua construção social de gênero ("tô tod $a$ enrolad $a$ na escola" - linha 07), o que contribui para corroborar a idéia de que, de fato, "na Internet, ninguém sabe que você é um cachorro" (TURKLE, 1996, p. 156). Tal uso, no entanto, passa a ser um cuidado constante para o qual Cris deve atentar sempre que estiver interagindo em eventos de letramento na Internet com alguém para quem queira ratificar seu posicionamento como uma menina, visto que o não uso da marca de feminino em seu discurso pode chegar até a desfazer sua construção social como tal.

Um segundo aspecto que legitima sua constituição identitária de gênero se coaduna com reconhecimento da alteridade, já que é a partir do outro que construímos quem somos (FAIRCLOUGH, 1992). No excerto, o outro, representado por Sabrina, usa o vocábulo "amiga" (linhas 02 e 04) para se referir a Cris, o que também ajuda a ratificar a idéia de que Sabrina, de fato, a constrói socialmente como uma menina.

No segundo excerto, Cris discute com Sabrina a respeito de uma amiga em comum $(R \hat{o})$, comentando sobre fotos de uma festa em que essa amiga esteve, a roupa que usou e um suposto namorado com quem esteve na festa. Excerto 2:

01 CRIS - oi, Sabri, td bem com vc?

09 CRIS - ai, a Rô me mostrou as fotos da festa da prima dela. vc viu?

10 SABRINA - vi... que vestido era aquele!!!

11 CRIS - um verde mto lindo com decotão nas costas. arrasou ela!!!

12 SABRINA - eh as fotos ficaram ótimas...

13 CRIS - e o namorado dela, achei bonitinho ele. q vc achou?

14 SABRINA - mto fofo ele. mas é namorado ou ficante dela?

15 CRIS - ela me disse que era só ficante. mas se sou ela ficava direto com ele...

Nesse excerto, os diálogos são mais distribuídos, havendo uma alternância entre a troca dos turnos dos interactantes. Cris é a primeira a tomar o turno para comentar acerca de uma amiga que ambas têm em comum: $R \hat{o}$. 
Nota-se que Cris mudou, propositadamente, o assunto anterior do qual Sabrina estava tratando, talvez porque não se sentisse muito à vontade de falar sobre relacionamentos amorosos e, assim, evitar um comprometimento maior acerca de sua identidade e sexualidade, o que, de alguma forma, poderia comprometer a identidade social que estava construindo no momento da interação.

Contudo, nessa segunda parte da conversa, Cris parece construir sua identidade social como uma menina, até de forma mais evidente que no primeiro excerto, por meio dos itens lexicais dos quais faz uso em seu discurso ("um decotão nas costas" e "arrasou ela" - linha 11), e do vocábulo "bonitinho" (linha 13), no qual se destaca o uso o diminutivo (inho), que, numa prática de letramento dentro de uma visão essencialista, com a qual Cris lida muito bem, contribuem para corroborar sua constituição identitária, uma vez que tais itens lexicais, na concepção do senso-comum, seriam típicos do discurso das mulheres, o que Cris não só tem consciência, mas também chega até a brincar com seus usos, uma vez que ele está reificando, e ao mesmo tempo parece estar desconstruindo, alguns construtos cristalizados na vida social de como "ser" uma menina.

Ainda nesse excerto, Cris, de forma mais contundente, parece querer se posicionar interacionalmente como uma menina ao dizer que, se estivesse no lugar da sua amiga $R \hat{o}$, ficaria com o seu suposto namorado: "mas se sou ela ficava direto com ele..." (linha 14), o que contribui para construir Cris como alguém que, de fato, se interessa por meninos e, por conseguinte, ajuda a ratificar, perante Sabrina, sua identidade social de gênero (uma menina), que vai sendo co-construída discursivamente ao longo da relação dialógica de ambos os interactantes.

Parece-me coerente a proposição de que cada sujeito (Cris e Sabrina), sobretudo no último excerto, constrói uma identidade própria no espaço discursivo virtual, no momento da interação, que faz com que seja reconhecido e avaliado pelo outro, na comunidade de prática da qual estão participando, como um certo tipo de pessoa e não outra, e isso fica bastante evidente na presente análise. Eque, portanto, Cris, ao interagir com Sabrina na Internet, não está somente agindo como autor do seu texto, mas também, e principalmente, de si mesmo (TURKLE, 1996, p.157).

\section{Considerações Finais}

Por meio deste estudo, procurei mostrar como a(s) maneira(s) com nos posicionamos discursivamente, sobretudo em práticas de letramentos disponibilizadas nos / pelos espaços virtuais, contribuem para (re)construir quem somos no mundo 
social. De forma mais específica, pude perceber como se dá a construção identitária de gênero de Cris ao se envolver num evento de letramento em que ele se posiciona interacionalmente como uma menina numa conversa realizada numa sala de "bate-papo" na Internet com sua amiga Sabrina, cujo papel se torna fundamental na forma como Cris se constrói sociodiscursivamente como sujeito.

Nesse jogo estrutural dos sentidos, devemos, por conseguinte, buscar a interpretação ativa diante de uma realidade sem sentido metafísico, sem sentido imanente, que possibilite a criação constante de novas formas de agir. Devemos construir identidades, e subvertê-las quando estas não mais nos servirem (BUTLER, 2003).

À luz dessa visão pós-estruturalista, entendemos que nós não somos, no sentido metafísico, homens, mulheres, heterossexuais e homossexuais, mas estamos, como poderíamos estar outra coisa. E, por meio do mundo virtual, talvez a compreensão desse construto se evidencie ainda mais, uma vez que "a multiplicação contemporânea dos espaços faz de nós nômades de um novo estilo: em vez de seguirmos linhas de errância e de migração dentro de uma extensão dada, saltamos de uma rede a outra, de um sistema de proximidade ao seguinte. Os espaços se metamorfoseiam e se bifurcam a nossos pés, forçando-nos à heterogênese" (LÉVY, 1996, p. 25).

Oque quero dizer, a partir disso tudo, é que se entendemos que (re)construímos quem somos de forma discursiva, e isso, é claro, podendo se configurar nas mais diversas práticas de letramento nas quais nos engajamos, isto é, por meio da interação que estabelecemos com o(s) outro(s) diante de uma certa realidade, ainda que seja uma realidade virtual na mídia eletrônica, então isso significa que podemos, com base nessa perspectiva, sempre atribuir novos sentidos e uma nova liberdade ao modo como interpretamos essa realidade.

Cris, hoje, pode estar exercendo o "papel" de homem em algumas de suas comunidades de prática, mas está sendo construído como uma mulher ao interagir com sua amiga numa comunidade de prática virtual. Isso me leva a crer que, de fato, uma pessoa, ao se ver como mulher ou homossexual, não está expondo sua natureza, uma suposta essência do seu ser, mas está se interpretando e se construindo de uma forma que lhe permita criar sentidos no mundo social.

Deveríamos, portanto, pensar não mais em identidades estanques, mas em posições fluídas e múltiplas, em que a repressão e a desigualdade funcionam sim, mas que podem ser substituídas pelo próprio movimento dessas identidades. $\mathrm{E}$, contrariando Hamlet, célebre personagem de Shakespeare, talvez a grande 
questão, sobretudo no mundo virtual, não seja mais ser ou não ser, mas sim ser E não ser.

\section{Referências Bibliográficas}

BAKHTIN, Mikhail. Marxismo e Filosofia da Linguagem. 7. ed. São Paulo: Hucitec, 1981.

BLOOME, D. Necessary indeterminancy and microethnography study of reading as a social process. Journal of Research in Reading, 1993.

BLOOME, D.; BALEY, F. M. Studying language and literacy through events, particularity, and intertextuality. In: BEACH, R.; GREEN, J.; KAMIL, M.; SHANAHAN, T., 1992.

BUTLER, Judith. Problemas de gênero: feminismo e a subversão da identidade. Rio de Janeiro: Civilização Brasileira, 2003.

COPE, B.; KALANTZIS, M. (Eds.). Multiliteracies: literacy learning and the design of social futures. Londres: Routledge. 2000.

DU GAY, P. Organizing identity: making up people at work. In: Du Gay edition, 1997.

FAIRCLOUGH, Norman. Discourse and social change. Cambridge: Polity Press, 1992.

FRIDMAN, L. C. Vertigens pós-modernas. Rio de Janeiro: Relume Dumará, 2000.

GEE, J. P. Identity as an analytic lens for research in education. In: SECADA, W.

G. (Ed.). Review of Research in Education, 25, 2000-2001. The American Educational Research Association, 2001.

GILBERT, P. Discourses on gender and literacy: changing the stories. In: MUSPRATT, S.; LUKE, A.; FREEBOODY, P. (Eds.). Constructing Critical Literacies. Cresskill, N. J.: Hampton Press, Inc., 1997.

GINSBURG, C. O queijo e os vermes. São Paulo: Companhia das Letras, 1987.

GOFFMAN, E. Interaction ritual: Essays on face-to-face behavior. New York: Pantheon, 1967.

GRAFF, H. The legacies of literacy. The American Educational Research Association, 1994.

KLEIMAN, A. Modelos de letramento e as práticas de alfabetização na escola. In: KLEIMAN, A. (Ed.). Os significados do letramento. Campinas: Mercado de Letras, 1995.

LANKSHEAR, C.; GEE, J. P. Language literacy and the New Work Order. In: LANKSHEAR, C. Changing literacies. Buckingham: Open U Press, 1997. 
LANKSHEAR, C.; KNOBEL, M. Literacy, texts and difference in the electronic age. In: LANKSHEAR, C. Changing literacies. Buckingham: Open U Press, 1997.

Different worlds? Technology-mediated classroom learning and students social practices with new technologies in home and community settings. In: LANKSHEAR, C. Changing literacies. Buckingham: Open U Press, 1997.

LAVE, Jean; WENGER, Etienne . Prática, pessoa, mundo social. In: DANIELS, Harry (Org.). Uma introdução a Vygotsky. Trad. Marcos Bagno. São Paulo: Loyola, 2002. LÉVY, P. O que é virtual? São Paulo: Editora 34, 1996.

LUKE, C. Media literacy and cultural studies. In: MUSPRATT, S.; LUKE, A.; FREEBOODY, P. (Eds.).Constructing critical literacies. Cresskill, N. J.: Hampton Press, Inc., 1997.

MARCHUSCHI, L. A. Linearização, cognição e referência: o desafio do hipertexto. IV Colóquio da Associação Latinoamericana de Analistas do Discurso. Santiago do Chile, 1999.

MOITA LOPES, L. P. Pesquisa interpretativa em lingüística aplicada: a linguagem como condição e solução. D.E.L.T.A. v. 10 /2., 1994.

. Identidades fragmentadas: A construção discursiva de raça, gênero e sexualidade em sala de aula. Campinas, SP: Mercado de Letras, 2003.

. A construção do gênero e do letramento na escola: como um tipo de conhecimento gera outro. Investigações. Lingüística e Teoria Literária, v. 17, n. 2, 2005.

ORLANDI, Eni Puccinelli. Análise do Discurso: princípios e procedimento. 3. ed. Campinas, SP: Pontes, 2001.

SCRIBNER, S.; COLE, M. The psycology of literacy. Cambrigde, Mass.: Havard University Press, 1981.

SIGNORINI, Inês. A letra dá a vida mas também pode matar. Os sem leitura diante da escrita. Leitura: teoria e prática, 1995.

SIGNORINI, Inês. (Org.). Lingua(gem) e identidade: elementos para uma discussão no campo aplicado. Campinas: Mercado de Letras, 1998.

STREET, B. Literacy in theory and practice. Cambridge: Cambridge University Press, 1995.

TURKLE, S. Parallel Lives: "Working on identity in virtual space". In: GRODIN, D.; LINDOLF, T. R. (Eds.). Constructing the self in a mediated world. Londres: Sage, 1996. 